Abstracta Iranica Abstracta Iranica

Revue bibliographique pour le domaine irano-aryen

Volume 32-33 | 2013

Comptes rendus des publications de 2009-2010

\title{
Antonio Invernizzi, Carlo Lippolis (eds.). Nisa Partica. Ricerche nel complesso monumentale arsacide 1990-2006
}

Laurianne Martinez-Sève

\section{(2) OpenEdition \\ 1 Journals}

Édition électronique

URL : http://journals.openedition.org/abstractairanica/40128

DOI : 10.4000/abstractairanica.40128

ISSN : 1961-960X

Éditeur :

CNRS (UMR 7528 Mondes iraniens et indiens), Éditions de l'IFRI

Édition imprimée

Date de publication : 1 décembre 2013

ISSN : 0240-8910

Référence électronique

Laurianne Martinez-Sève, «Antonio Invernizzi, Carlo Lippolis (eds.). Nisa Partica. Ricerche nel complesso monumentale arsacide 1990-2006», Abstracta Iranica [En ligne], Volume 32-33 | 2013, document 19, mis en ligne le 01 juillet 2016, consulté le 26 septembre 2020. URL : http:// journals.openedition.org/abstractairanica/40128; DOI : https://doi.org/10.4000/abstractairanica 40128

Ce document a été généré automatiquement le 26 septembre 2020.

Tous droits réservés 


\title{
Antonio Invernizzi, Carlo Lippolis (eds.). Nisa Partica. Ricerche nel complesso monumentale arsacide 1990-2006
}

\author{
Laurianne Martinez-Sève
}

\section{RÉFÉRENCE}

Nisa Partica. Ricerche nel complesso monumentale arsacide 1990-2006. Firenze, Le Lettere, 2008, xi+401 p., ill. (Monografie di Mesopotamia, IX ; Centro Ricerche Archeologiche e Scavi di Torino per il Medio Oriente e l'Asia, Missione in Turkmenistan, I)

1 Ce gros volume constitue la publication des fouilles menées à Vieille Nisa depuis 1990 par le Centro Ricerche Archeologiche e Scavi di Torino per il Medio Oriente e l'Asia, sous la direction de A. Invernizzi et C. Lippolis en collaboration avec l'Institut d'Archéologie de l'Académie des Sciences de l'URSS puis avec le Département National de Protection et Conservation des Monuments Historiques et Culturels du Turkménistan. Vieille Nisa fut l'une des résidences royales des premiers Parthes et constitue sans doute Mithridatokert, fondée par Mithridate $\mathrm{I}^{\mathrm{er}}$ dans le courant $\mathrm{du} \mathrm{II}^{\mathrm{e}} \mathrm{s}$. av. J.-C. Les travaux qui ont été menés durant le $\mathrm{XX}^{\mathrm{e}}$ s., notamment par la JuTAKE, avaient révélé un ensemble de bâtiments monumentaux et permis la découverte de plusieurs trouvailles spectaculaires. Les fouilleurs italiens se sont concentrés sur le secteur Sud-Ouest, là où se trouve la Salle Ronde, bâtiment généralement considéré comme dévolu au culte dynastique, peut-être de Mithridate $\mathrm{I}^{\mathrm{er}}$. Leurs objectifs étaient de procéder à des contrôles stratigraphiques, d'étudier l'architecture du bâtiment et de récupérer les fragments des statues d'argile qu'il abritait et que les fouilleurs russes avaient renoncé à prélever faute de moyens de conservation et de restauration. Les résultats montrent que ces objectifs ont été pleinement atteints voire dépassés : un nouvel édifice, occupant un espace de $41 \mathrm{~m}$ sur $42 \mathrm{~m}$ et baptisé «l'Édifice Rouge » en 
raison de sa décoration peinte, a été mis au jour au Nord de la Salle Ronde. Implanté sur le sol vierge, il date d'une phase d'occupation plus ancienne que celle à laquelle se rattachent les autres constructions. C'était un bâtiment administratif qui faisait sans doute partie d'un complexe plus important, s'étendant dans des secteurs non fouillés. La publication, richement illustrée, est impressionnante par sa qualité scientifique et matérielle. Elle débute par une étude de la Salle Ronde dont la nouvelle reconstitution proposée remplace celle qui datait de l'époque de G. A. Pugačenkova et N. I. Krašeninnikova, et oblige à placer sur le sol les statues qui y étaient abritées. Suit la publication de l'Édifice Rouge, dont le plan est typique de l'Asie Centrale: on y accédait par un portique, qui donnait par l'intermédiaire d'une petite pièce dans une grande salle tétrastyle de forme à peu près carrée, entourée d'une rangée de pièces étroites, elles-mêmes bordées de couloirs périphériques. Le bâtiment était exceptionnel par son décor peint et sa décoration architecturale en pierre. Il connut deux états successifs et était surmonté par une construction islamique. Le reste de l'ouvrage est consacré à l'étude de tout le matériel mis au jour: les éléments de sculpture d'argile, présentés de manière particulièrement suggestive alors qu'ils sont très fragmentaires ; les éléments architecturaux, qui donnent lieu à une étude des techniques de construction; la céramique (parthe et islamique); les objets, dont 22 sphéroïdes de plâtre portant des empreintes, qui servaient peut-être dans un contexte rituel; quelques inscriptions. Sont aussi donnés les résultats d'analyses archéobotaniques et d'analyses sur des éléments métalliques. On dispose donc d'une publication soignée et de très haut niveau, qui témoigne du travail exemplaire conduit par la mission italienne, dont les résultats sont en outre portés rapidement à la connaissance du public.

\section{AUTEURS}

\section{LAURIANNE MARTINEZ-SÈVE}

Université de Lille 3 